Onkologie 1985;8(suppl. 1):2

\title{
Impressum, Vol. 8, Supplement 1, 1985
}

\section{s. karger}

Verlag für Medizin und Naturwissenschaften GmbH, Postfach 1724, D-8034 Germering

Wissenschaftlicher Beirat

H. W. Bauer, Berlin; H. Denck, Wien; V. Diehl, Köln; F. Douwes, Göttingen; P. Drings, Heidelberg; S. Eckhardt, Budapest; H. Ehrhardt, München; W. M. Gallmeier, Nürnberg; H. Gerhartz, Berlin; E. H. Graul, Marburg/Lahn; R. Gross, Köln; H. Heimpel, Ulm; K. P. Hellriegel, Berlin; Ch. Herfarth, Ulm; H. W. von Hey den, Göttingen; J. H. Holzner, Wien; R. Hünig, Basel; W. Hunstein, Heidelberg; U. R. Kleeberg, Hamburg; H. O. Klein, Köln; H.

Löffler, Kiel; U. Mohr, Hannover; K. Munk, Heidelberg; G. A. Nagel, Göttingen; A. Pfleiderer, Freiburg; E. Scherer, Essen; S. Seeber, Leverkusen; H. J. Senn, St. Gallen; A. Stacher, Wien; St. Tanneberger, Berlin/DDR; W. Vahlensieck, Bonn; H. D. Waller, Tubingen; M. Wannen-macher, Freiburg; W. Wilmanns, München; K. Wilms, Würzburg; K. zum Winkel, Heidelberg; H. Wrba, Wien.

Schriftleitung: S. Eckhardt, Budapest J. H. Holzner, Wien G. A. Nagel, Göttingen

Anzeigen

S. Karger Verlag für Medizin und Naturwissenschaften GmbH, Postfach 1724, 8034 Germering, Telefon (089) 844021.

Für den Inhalt außerhalb des redaktionellen Teiles (insbesondere Anzeigen, Industrieinformationen, Pressezitate und Kongreßinfor-mationen) übernehmen Herausgeber und Verlag keine Gewähr.

Eine Markenbezeichnung kann warenzeichenrechtlich geschützt sein, auch wenn bei ihrer Verwendung in dieser Zeitschrift das Zeichen ${ }^{\circledR}$ oder ein anderer Hinweis auf etwa bestehende Schutz-rechte fehlen sollte.

Alle Rechte, insbesondere das Recht der Vervielfältigung und Mikrokopie sowie der Ubersetzung, vorbehalten. Nachdruck, auch auszugsweise, nur mit Genehmigung des Verlages. (C) Copyright 1985 by S. Karger Verlag für Medizin und Naturwissenschaften GmbH, Postfach 1724, D-8034 Germering

Satz und Druck: Walter Biering GmbH, Grafischer Betrieb, 8000 München 45

Ladenpreis dieses Sonderheftes DM 18,- incl. MwSt. Abonnenten erhalten es unberechnet. Bezugspreis der Zeitschrift:

Für Jahrgang 8,1985, DM 147,-/öS 1029,-/SFr. 140, 1 Einzelheft kostet DM 27,-/öS 189,-/SFr. 26,-, einschließlich MwSt., zuzüglich Postgebühren. 